\title{
Aplikasi Penyandian Record Menggunakan Metode Twofish
}

\author{
Asmawi \\ STMIK Budi Darma Medan, Jl.Sisingamangaraja No.338 Simpang Limun Medan, Indonesia \\ asmawi.asma@yahoo.com
}

\begin{abstract}
Abstrak. Perkembangan teknologi semakin mengalami kemajuan, misalnya untuk keamanan data. Keamanan data merupakan hal yang sangat penting dalam menjaga kerahasiaan informasi terutama informasi yang sensitive yang hanya boleh diketahui isinya hanya pihak yang berhak saja, apalagi penyimpanan data dilakukan pada komputer, apabila data tersebut tidak diamankan terlebih dahulu maka data tersebut akan diketahui oleh pihak-pihak yang tidak berhak dengan adanya pengamanan data pada record maka data yang ada pada komputer tidak mudah dilihat dan tidak bisa dirubah oleh sembarangan pihak yang tidak bertanggung jawab sehingga data akan aman dan tidak bisa diganggu gugat oleh pihak manapun. Salah satu pengamanan data adalah dengan menggunakan sistem kriptografi yaitu penyandian isi informasi (plaintext) tersebut menjadi isi yang tidak bisa dipahami melalui proses enkripsi (enchipher) dan untuk memperoleh kembali informasi yang asli, dilakukan proses deskripsi (deschiper) disertai dengan menggunakan kunci yang benar. Penyandian data atau kriptografi adalah ilmu yang mempelajari tentang penyembunyian huruf atau tulisan sehingga membuat tulisan tersebut tidak dapat dibaca oleh orang yang tidak berkepentingan. Kriptografi sudah dipakai sejak jaman Julius Caesar dimana akan mengirimkan pesan kepada panglimanaya tetapi tidak mempunyai kurir pembawa pesan tersebut. Kriptografi mempunyai 2 (dua) bagian yang penting yaitu enkripsi dan deskripsi. Enkripsi adalah adalah proses dari penyandian pesan asli menjadi pesan yang tidak dapat diartikan seperti aslinya. Deskripsi adalah merubah pesan yang sudah diartikan menjadi aslinya pesan asli biasanya disebut plaintext, sedangkan pesan yang sudah diartikan disebut chipertext.
\end{abstract}

Kata Kunci : Kriptografi, Pesan Rahasia, Enkripsi, Dekripsi pada penyandian file record.

\begin{abstract}
Technological developments are increasingly progressing, for example for data security. Data security is very important in maintaining the confidentiality of information, especially sensitive information, which only authorized parties can know, moreover data storage is done on a computer, if the data is not secured in advance then the data will be known by the parties who are entitled to it. is not entitled to the security of data on the record, the data on the computer is not easily seen and cannot be changed by irresponsible parties so that the data will be safe and cannot be contested by any party One of the data safeguards is by using a cryptographic system, which is the encryption of the contents of the information (plaintext) into incomprehensible content through an encryption process (encoding) and to retrieve the original information, a description process (deschiper) is carried out accompanied by using the correct key. Data encryption or cryptography is the study of hiding letters or writings so that they cannot be read by unauthorized people. Cryptography has been used since the time of Julius Caesar, who sent messages to the commander but did not have a courier to carry the message. Cryptography has 2 (two) important parts, namely encryption and description. Encryption is the process of encrypting the original message into a message that cannot be interpreted as the original. Description is to change a message that has been interpreted to be the original message, usually called plaintext, while the message that has been interpreted is called ciphertext.
\end{abstract}

Keyword : Cryptography, Secret Message, Encryption, Decryption on encoding file records.

\section{PENDAHULUAN}

Keamanan data merupakan hal yang sangat penting dalam menjaga kerahasiaan informasi terutama informasi yang sensitif yang hanya boleh diketahui isinya hanya oleh pihak yang berhak saja, apalagi penyimpanan data dilakukan pada komputer, apabila data tersebut tidak diamankan terlebih dahulu maka data tersebut akan diketahui oleh pihak-pihak yang tidak berhak dengan adanya pengamanan data pada record maka data yang ada pada komputer tidak mudah dilihat dan 
tidak bisa dirubah oleh sembarangan pihak yang tidak bertanggung jawab khususnya penyandian pada database pada laptop anda [1], [2]. Aplikasi penyandian record memberikan manfaat yang sangat besar dalam industry pemonggraman saat ini. Salah satunya adalah dalam penyimpanan data dan kerahasiaan data tersebut tidak bisa diganggu gugat oleh pihak yang tidak berkepentingan, salah satunya adalah dalam penyimpanan data atau informasi yang sangat rahasia didalamnya. Data record yang telah disandiakan akan lebih sulit untuk membukanya oleh orang-orang lain yang tidak bertanggung jawab. Selain pada proses penyandian data record juga bisa digunakan dalam proses penyandian field dan yang lain-lain[3], [4].

Tujuan penelitian adalah untuk melakukan proses penyandian data dan mengenkripsi dan mendeskripsi menggunakan metode twofish, Menerapakan metode twofish dan penyandian record [5], [6] menggunakan metode tersebut dan menerapkan metode twofish dan memprosesnya menggunakan Microsoft visual basic net 2008.

\section{METODOLOGI PENELITIAN}

\subsection{Kriptografi}

Kriptografi berasal dari bahasa Yunani, crypto dan graphia. Crypto berarti secret (rahasia) dan graphia berarti writing (tulisan). Jadi kriptografi berarti secret writing (tulisan rahasia). Menurut terminologinya, kriptografi adalah ilmu dan seni untuk menjaga keamanan pesan ketika pesan dikirim dari suatu tempat ketempat lain [4], [7]. Kriptografi pada dasarnya sudah dikenal sejak lama. Menurut catatan sejarah, kriptografi sudah digunakan oleh bangsa Mesir sejak 4000 tahun yang lalu oleh raja - raja Mesir pada saat perang untuk mengirimkan pesan rahasia kepada panglima perangnya melalui kurir - kurinya. Orang yang melakukan penyandian ini disebut kriptografer, sedangkan orang yang mendalami ilmu dan seni dalam membuka atau memecahkan suatu algoritma kriptografi tanpa harus mengetahui kuncinya disebut kriptanalis. 4 tujuan mendasar:

1. Kerahasiaan (Confidentiality)

Yaitu layanan agar isi pesan yang dikirimkan tetap rahasia dan tidak diketahui oleh pihak lain (kecuali pihak pengirim, pihak penerima / pihak - pihak memiliki ijin). Layanan ini direalisasikan dengan menyandikan pesan menjadi cipherteks.

2. Integritas data (data integrity)

Adalah berhubungan dengan penjagaan dari perubahan data secara tidak sah. Untuk menjaga integritas data, sistem harus memiliki kemampuan untuk mendeteksi manipulasi data oleh pihak-pihak yang tidak berhak, antara lain menyangkut penyisipan, penghapusan, dan pensubtitusian data lain ke dalam data yang sebenarnya.

3. Otentikasi (authentication)

Yaitu layanan yang berhubungan dengan identifikasi. Baik otentikasi pihak-pihak yang terlibat dalam pengiriman data maupun otentikasi keaslian data/informasi.

4. Nirpenyangkalan (non-repudiation)

Yaitu layanan yang dapat mencegah suatu pihak untuk menyangkal aksi yang dilakukan sebelumnya (menyangkal bahwa pesan tersebut berasal dirinya).

Dalam penelitian ini menggunakan pengkodean ASCII, karena kode ASCII, karena kode ASCII merupakan kode standar yang digunakan dalam komputer mikro atau Personal Computer (PC). Pengujian dan aplikasi penelitian ini nantinya akan menggunakan personal komputer.

\subsection{Twofish}

Pada tahun 1972 dan 1974, US the National Bureau of Standards (sekarang bernama the National Institute of Standards and Technology, atau NIST) mengeluarkan publikasi pertama untuk sebuah standar enkripsi, yang menghasilkan algoritma data Encryption Standard (DES), yang tidak dapat disangkal sebagai algoritma kriptografi yang sangat terkenal dan sangat berhasil [8], [9]. Algoritma Twofish merupakan algoritma kuat yang sampai saat ini dinyatakan aman karena masih 
belum ada serangan kriptanalisis yang benar - benar dapat mematahkan algoritma ini. Algoritma ini juga tidak dipatenkan sehingga penggunaannya pada alat enkripsi tidak perlu mengeluarkan biaya.

\subsection{Tujuan Desain TwoFish}

Algoritma Twofish didesain untuk memenuhi kriteria yang ditetapkan oleh NIST untuk sayembara penentuan standar algoritma[10] . Kriteria tersebut diantaranya adalah :

1. Menggunakan 128-bit enkripsi dengan metode blok cipher.

2. Panjang kunci 128 bit, 192 bit, dan 256 bit.

3. Tidak memiliki kunci lemah

4. Efisien baik jika digunakan di Intel Pentium Pro maupun perangkat lunak ataupun keras lainnya

5. Memiliki desain yang fleksibel sehingga dapat digunakan untuk stream chiper, hash function, dan MAC.

6. Design yang sederhana.

Kriteria tambahan yang dimiliki oleh algoritma Twofish adalah :

1. Dapat menerima kunci lebih dari 256 bit

2. Untuk versi dengan optimasi penuh proses enkripsi data dapat dilakukan kurang dari 500 clock cycle per blok pada Pentium, Pentium Pro.

3. Untuk pemrosesan 32 blok dengan 128 bit kunci dapat memakan waktu yang lebih sedikit.

4. Tidak memiliki operasi yang dapat mengurangi efisiensi jika digunakan pada mikroprosesor 8bit, 16-bit, 32-bit maupun 64 bit.

5. Memiliki berbagai variasi performansi dari key schedule.

\subsection{Blok Pembangun TwoFish}

Secara garis besar algoritma twofish dibangun dari beberapa algoritma utama, algoritma algoritma tersebut diambil dari prinsip pembangunan algoritma cipher blok. Ada 6 prinsip yang digunakan yaitu :

1. Jaringan Feistel

Hampir semua algoritma cipher blok bekerja dalam model jaringan Feistel. Jaringan Feistel ditemukan oleh Horst Feistel dalam desainnya tentang Lucifer, dan dipopulerkan oleh DES. Jaringan Feistel adalah metode umum untuk mentransformasi fungsi apapun (biasa disebut fungsi F) ke dalam permutasi. Beberapa algoritma kriptografi lain yang menggunakan jaringan Feistel misalnya LOKI, GOST, FEAL, Blowfish, Khufu Khafre, dan RC-5. Model jaringan Feistel bersifat reversible, untuk proses enkripsi dan dekripsi, sehingga kita tidak perlu membuat algoritma baru untuk mendekripsi cipherteks menjadi plainteks.

2. Kotak S (S-Boxes)

Kotak-S adalah matriks yang berisi subst itusi non-linear yang memetakan satu atau lebih bit dengan satu atau lebih bit yang lain dan digunakan di banyak cipher blok. Kotak-S memiliki ukuran input dan ukuran output yang bervariasi. Ada empat pendekatan yang digunakan dalam mengisi Kotak-S : dipilih secara acak, dipilih secara acak lalu diuji, dibut oleh orang, dihitung secara matematis. Kotak-S pertama digunakan di Lucifer, lalu DES dan diikuti banyak algoritma enkripsi yang lain. Twofish menggunakan empat buah 8x8 bit Kotak-S yang berbeda, bijektif, dan bergantung pada kunci. Kotak-S ini dibuat menggunakan 8 x8 bit permutasi dan material kunci.

3. MDS Matrices

Kode MDS (Maximum Distance Separable) pada sebuah field adalah pemetaan liner dari $\mathrm{x}$ elemen field ke y elemen field, dan menghasilkan vektor komposit $\mathrm{x}+\mathrm{y}$ elemen, dengan ketentuan bahwa jumlah minimum dari elemen bukan nol pada setiap vektor bukan nol paling sedikit $\mathrm{y}+1$. Dengan kata lain, jumlah elemen yang berbeda diantara dua vektor berbeda yang dihasilkan oleh pemetaan MDS paling sedikit $\mathrm{y}+1$. Dapat dibuktikan dengan mudah bahwa tidak ada pemetaan yang dapat memiliki jarak pisah yang lebih besar diantara dua vektor yang 
berbeda, maka disebut jarak pisah maksimum (maximum distance separable). Pemetaan MDS dapat direpresentasikan dengan sebuah MDS matriks yang teridiri dari $\mathrm{x} \times \mathrm{y}$ elemen.

Kode perbaikan-kesalahan Reed-Solomon (RS) adalah MDS. Kondisi yang diperlukan untuk sebuah $\mathrm{x} \times \mathrm{y}$ matriks untuk menjadi MDS adalah semua kemungkinan submatriks kotak, yang diperoleh dengan membuang kolom atau baris, adalah tidak singular. Serge Vaudenay pertama kali mengajukan matriks MDS sebagai elemen desain kode. Shark dan Square menggunakan matrika MDS, meskipun konstruksinya pertama kali ditemukan di kode Manta yang tidak dipublikasikan. Twofish menggunakan matriks MDS tunggal 4x4.

4. Transformasi Pseudo Hadamard

Transformasi Pseudo-Hadamard (PHT) adalah sebuah operasi pencampuran sederhana yang berjalan secara cepat dalam perangkat lunak. 32-bit PHT dengan dua masukkan didefinisikan sebagai :

$$
\begin{gathered}
a^{\prime}=a+b \bmod 2^{32} \\
b^{\prime}=a+2 b \bmod 2^{32}
\end{gathered}
$$

SAFER menggunakan 8-bit PHT untuk difusinya. Twofish menggunakan 32-bit PHT untuk mengubah keluaran dari fungsi g- nya. PHT ini dapat dieksekusi dalam dua opcodes di mikroprosesor modern seperti keluarga Pentium.

5. Whitening

Whitening, sebuah teknik meng-XOR-kan material kunci sebelum putaran pertama dan setelah putaran terakhir, digunakan oleh Merkle dalam Khufu/Khafre, dan ditemukan oleh Rivest untuk DES-X. Whitening menambah tingkat kesulitan serangan pencarian kunci terhadap ciphertext, dengan menyembunyikan masukkan spesifik terhadap putaran pertama dan putaran terakhir dari fungsi $\mathrm{F}$.

Twofish meng-XOR-kan 128-bit sub-kunci sebelum putaran Feistel yang pertama, dan 128-bit lagi setelah putaran Feistel terakhir. Sub-kunci ini diperhitungkan dengan cara yang sama seperti sub-kunci putaran, tetapi tidak digunakan di tempat lain dalam cipher.

6. Penjadwalan Kunci

Penjadwalan kunci adalah proses pengubahan bit-bit kunci menjadi sub-kunci tiap putaran yang dapat digunakan oleh cipher. Twofish memerlukan banyak material kunci dan memiliki penjadwalan kunci yang rumit. Untuk memfasilitasi analisis, penjadwalan kunci menggunakan primitif yang sama seperti fungsi putaran.

\subsection{Algoritma Twofish}

Twofish merupakan algoritma kriptografi kunci simetrik cipher blok dengan panjang setiap blok adalah tetap 128 bit. Sedangkan kunci yang dapat diterima adalah: 128, 192, atau 256 bit. Twofish memanfaatkan teknik pemanipulasian bit, kotak permutasi/pemutihan, jaringan feistel, pemutaran ulang dengan pergiliran kunci dengan jumlah perputaran dan pergiliran kunci sebanyak 16 kali, tranformasi pseudo-Hadamard, ekspansi dan filter, dan kotak MDS (Most Distance Separable). 


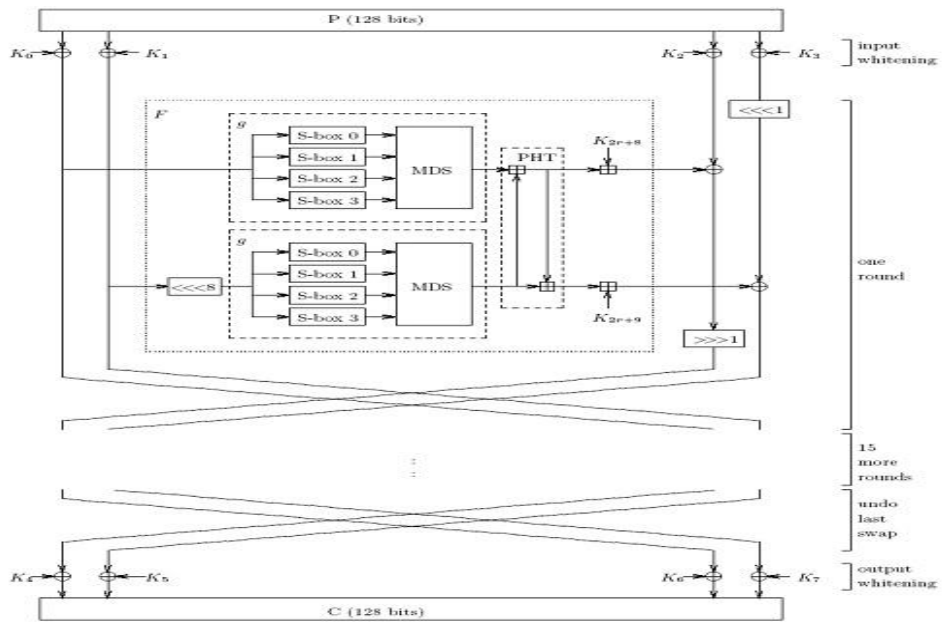

Gambar 1. Struktur Algoritma TwoFish

\section{HASIL DAN PEMBAHASAN}

\subsection{Proses Pembentukan S-Box}

Proses pembentukan tabel $S$-Boxterdiri atas 8 (delapan) proses utama. Dalam prosesnya, pembentukan tabel S-Box memerlukan inputkunci dengan panjang 128 bit biner atau 16 karakter ascii. Untuk lebih jelas, proses ini dapat dilihat pada contoh berikut :

Misalkan inputkey = 'STMIK BUDIDARMA ', maka proses pembentukan tabel S-Box dalam heksadesimal adalah sebagai berikut :

LANGKAH 1 - Inisialisasi nilai TT[0] ... TT[7]

$\mathrm{TT}[0]=726 \mathrm{~A} 8 \mathrm{~F} 3 \mathrm{~B}$

$\mathrm{TT}[1]=\mathrm{E} 69 \mathrm{~A} 3 \mathrm{~B} 5 \mathrm{C}$

$\mathrm{TT}[2]=\mathrm{D} 3 \mathrm{C} 71 \mathrm{FE} 5$

$\mathrm{TT}[3]=\mathrm{AB} 3 \mathrm{C} 73 \mathrm{D} 2$

$\mathrm{TT}[4]=4 \mathrm{D} 3 \mathrm{~A} 8 \mathrm{~EB} 3$

$\mathrm{TT}[5]=0396 \mathrm{D} 6 \mathrm{E} 8$

$\mathrm{TT}[6]=3 \mathrm{D} 4 \mathrm{C} 2 \mathrm{~F} 7 \mathrm{~A}$

$\mathrm{TT}[7]=9 \mathrm{EE} 27 \mathrm{CF} 3$

LANGKAH 2 - Pecah kunci menjadi 4 kelompok besar dan masukkan pada T[0] ... T[3]

Kunci : 'STMIK BUDIDARMA '

Hasil S:DEC=HEX

Kode ascii dari ' $\mathrm{S}$ ' $=83=53$

Kode ascii dari ' $\mathrm{T}$ ' $=84=54$

Kode ascii dari 'M' $=77=4 \mathrm{D}$

Kode ascii dari 'I' $=73=49$

Kode ascii dari ' $\mathrm{K}$ ' $=75=4 \mathrm{~B}$

Kode ascii dari ' ' $=32=20$

Kode ascii dari 'B' $=66=42$

Kode ascii dari 'U' $=85=55$

Kode ascii dari 'D' $=68=44$

Kode ascii dari 'I' $=73=49$

Kode ascii dari 'D' $=68=44$ 
Kode ascii dari 'A' $=65=41$

Kode ascii dari 'R' $=82=52$

Kode ascii dari ' $\mathrm{M}$ ' $=77=4 \mathrm{D}$

Kode ascii dari 'A' $=65=41$

Kode ascii dari ' ' $=32=20$

Kunci $($ dalam heksa $)=$ 53544D494B20425544494441524D4120

$\mathrm{T}[0]=\mathrm{K}[0]=53544 \mathrm{D} 49$

$\mathrm{T}[1]=\mathrm{K}[1]=4 \mathrm{~B} 204255$

$\mathrm{T}[2]=\mathrm{K}[2]=44494441$

$\mathrm{T}[3]=\mathrm{K}[3]=524 \mathrm{D} 412$

LANGKAH 3 - Untuk n = 4 sampai 255, lakukan prosedur berikut.

$\mathrm{n}=4$

$\rightarrow \mathrm{X}=\mathrm{T}[0]+\mathrm{T}[3]=53544 \mathrm{D} 49+524 \mathrm{D} 4120=\mathrm{A} 5 \mathrm{~A} 18 \mathrm{E} 69$

-> X >> 3 (Shift Right 3 bit) = A5A18E69 >> $3=14 \mathrm{~B} 431 \mathrm{CD}$

$\mathrm{X}$ AND $7=$ A5A18E69 AND 7(10) $=1$

$\mathrm{T}[4]=\mathrm{X} \gg \mathrm{XOR}$ TT[X AND 7] $=14 \mathrm{~B} 431 \mathrm{CD}$ XOR TT[1] $=$ F22E0A91

$\mathrm{n}=5$

$\mathrm{n}=11$

$->\mathrm{X}=\mathrm{T}[7]+\mathrm{T}[10]=8288 \mathrm{E} 7 \mathrm{~A} 5+7 \mathrm{~F} 8 \mathrm{E} 5 \mathrm{CF} 4=02174499$

-> X >> 3 (Shift Right 3 bit $)=02174499>>3=0042 \mathrm{E} 893$

$\mathrm{X}$ AND $7=02174499$ AND $7(10)=1$

$\mathrm{T}[11]=\mathrm{X} \gg>\mathrm{XOR}$ TT $[\mathrm{X}$ AND 7] $=0042 \mathrm{E} 893 \mathrm{XOR} \mathrm{TT}[1]=\mathrm{E} 6 \mathrm{D} 8 \mathrm{D} 3 \mathrm{CF}$

$\mathrm{n}=12$

dan seterus nya...........

LANGKAH 4 - Untuk n = 0 sampai 22, lakukan prosedur berikut.

$\mathrm{n}=0$

$\mathrm{T}[1]=\mathrm{T}[1]+\mathrm{T}[90]=4 \mathrm{~B} 204255+773 \mathrm{D} 8 \mathrm{DCD}=\mathrm{C} 25 \mathrm{DD} 022$

$\mathrm{T}[0]=\mathrm{T}[0]+\mathrm{T}[89]=53544 \mathrm{D} 49+1 \mathrm{CE} 3 \mathrm{~B} 995=703806 \mathrm{DE}$

$\mathrm{n}=1$

$\mathrm{n}=2$

$\mathrm{T}[2]=\mathrm{T}[2]+\mathrm{T}[91]=44494441+72 \mathrm{~A} 1384 \mathrm{~A}=\mathrm{B} 6 \mathrm{EA} 7 \mathrm{C} 8 \mathrm{~B}$

$\mathrm{n}=3$

$\mathrm{T}[3]=\mathrm{T}[3]+\mathrm{T}[92]=524 \mathrm{D} 4120+32715 \mathrm{E} 5 \mathrm{D}=84 \mathrm{BE} 9 \mathrm{~F} 7 \mathrm{D}$

$\mathrm{n}=4$

$\mathrm{T}[4]=\mathrm{T}[4]+\mathrm{T}[93]=\mathrm{F} 22 \mathrm{E} 0 \mathrm{~A} 91+\mathrm{DA} 2 \mathrm{DBD} 1 \mathrm{~B}=\mathrm{CC} 5 \mathrm{BC} 7 \mathrm{AC}$

$\mathrm{n}=5$

$\mathrm{T}[5]=\mathrm{T}[5]+\mathrm{T}[94]=3 \mathrm{AE} 5 \mathrm{E} 6 \mathrm{E} 6+7847 \mathrm{E} 666=\mathrm{B} 32 \mathrm{DCD} 4 \mathrm{C}$

$\mathrm{n}=6$

$\mathrm{T}[6]=\mathrm{T}[6]+\mathrm{T}[95]=91079997+6 \mathrm{~F} 37 \mathrm{ACED}=003 \mathrm{~F} 4684$

$\mathrm{n}=7$

$\mathrm{T}[7]=\mathrm{T}[7]+\mathrm{T}[96]=8288 \mathrm{E} 7 \mathrm{~A} 5+\mathrm{C} 7 \mathrm{~F} 23 \mathrm{E} 8 \mathrm{C}=4 \mathrm{~A} 7 \mathrm{~B} 2631$

$\mathrm{n}=8$

$\mathrm{T}[8]=\mathrm{T}[8]+\mathrm{T}[97]=33 \mathrm{DAF} 13 \mathrm{C}+8 \mathrm{AA} 18387=\mathrm{BE} 7 \mathrm{C} 74 \mathrm{C} 3$

$\mathrm{n}=9$

$\mathrm{T}[9]=\mathrm{T}[9]+\mathrm{T}[98]=\mathrm{DE} 1 \mathrm{~F} 04 \mathrm{E} 1+$ 03CBFBD5 $=$ E1EB00B6 $\mathrm{n}=10$ 
$\mathrm{T}[10]=\mathrm{T}[10]+\mathrm{T}[99]=7 \mathrm{~F} 8 \mathrm{E} 5 \mathrm{CF} 4+\mathrm{DDA} 76 \mathrm{AFD}=5 \mathrm{D} 35 \mathrm{C} 7 \mathrm{~F} 1$

$\mathrm{n}=11$

$\mathrm{T}[11]=\mathrm{T}[11]+\mathrm{T}[100]=\mathrm{E} 6 \mathrm{D} 8 \mathrm{D} 3 \mathrm{CF}+\mathrm{F} 2290 \mathrm{E} 6 \mathrm{D}=\mathrm{D} 901 \mathrm{E} 23 \mathrm{C}$

$\mathrm{n}=12$

dan seterusnya...

LANGKAH 5 - Set nilai untuk variabel di bawah ini.

$\mathrm{X}=32 \mathrm{FFA} 237$

$\mathrm{Z}=\mathrm{T}$ [59] OR $01000001=\mathrm{FFF} 256 \mathrm{~A} 8 \mathrm{OR} 01000001=\mathrm{FFF} 256 \mathrm{~A} 9$

$\mathrm{Z}=\mathrm{Z}$ AND FF7FFFFF $=$ FFF256A9 AND FF7FFFFF $=$ FF7256A9

$\mathrm{X}=\mathrm{X}$ AND FF7FFFFF $=32 \mathrm{FFA} 237$ AND FF7FFFFF $=31 \mathrm{~F} 1 \mathrm{~F} 8 \mathrm{E} 0$

LANGKAH 6 - Untuk n = 0 sampai 255, lakukan prosedur berikut.

$\mathrm{n}=0$

$\mathrm{X}=(31 \mathrm{~F} 1 \mathrm{~F} 8 \mathrm{E} 0$ AND FF7FFFFF $)+\mathrm{FF} 7256 \mathrm{~A} 9=30 \mathrm{E} 44 \mathrm{~F} 89$

$\mathrm{T}[0]=703806 \mathrm{DE}]$ AND 00FFFFFF XOR 30E44F89 = 30DC4957

$\mathrm{n}=1$

$\mathrm{X}=(30 \mathrm{E} 44 \mathrm{~F} 89$ AND FF7FFFFF $)+$ FF7256A9 $=$ 2FD6A632

$\mathrm{T}[1]=\mathrm{C} 25 \mathrm{DD} 022]$ AND 00FFFFFF XOR 2FD6A632 = 2F8B7610

$\mathrm{n}=2$

$\mathrm{X}=(2 \mathrm{FD} 6 \mathrm{~A} 632 \mathrm{AND}$ FF7FFFFF $)+\mathrm{FF} 7256 \mathrm{~A} 9=2 \mathrm{EC} 8 \mathrm{FCDB}$

$\mathrm{T}[2]=\mathrm{B} 6 \mathrm{EA} 7 \mathrm{C} 8 \mathrm{~B}]$ AND 00FFFFFF XOR 2EC8FCDB $=2 \mathrm{E} 228050$

$\mathrm{n}=3$

$\mathrm{X}=(2 \mathrm{EC} 8 \mathrm{FCDB}$ AND FF7FFFFF $)+$ FF7256A9 $=$ 2DBB5384

$\mathrm{T}[3]=84 \mathrm{BE} 9 \mathrm{~F} 7 \mathrm{D}]$ AND 00FFFFFF XOR 2DBB5384 = 2D05CCF9

$\mathrm{n}=4$

$\mathrm{X}=($ 2DBB5384 AND FF7FFFFF $)+$ FF7256A9 $=$ 2CADAA2D

$\mathrm{T}[4]=\mathrm{CC} 5 \mathrm{BC} 7 \mathrm{AC}]$ AND 00FFFFFF XOR 2CADAA2D = 2CF66D81

$\mathrm{n}=5$

$\mathrm{X}=($ 2CADAA2D AND FF7FFFFF $)+$ FF7256A9 $=$ 2BA000D6

$\mathrm{T}[5]=\mathrm{B} 32 \mathrm{DCD} 4 \mathrm{C}]$ AND 00FFFFFF XOR 2BA000D6 = 2B8DCD9A

$\mathrm{n}=6$

$\mathrm{X}=(2 \mathrm{BA} 000 \mathrm{D} 6 \mathrm{AND}$ FF7FFFFF $)+\mathrm{FF} 7256 \mathrm{~A} 9=2 \mathrm{~A} 92577 \mathrm{~F}$

$\mathrm{T}[6]=003 \mathrm{~F} 4684]$ AND 00FFFFFF XOR 2A92577F $=2 \mathrm{AAD} 11 \mathrm{FB}$

$\mathrm{n}=7$

$\mathrm{X}=(2 \mathrm{~A} 92577 \mathrm{~F}$ AND FF7FFFFF $)+\mathrm{FF} 7256 \mathrm{~A} 9=2984 \mathrm{AE} 28$

$\mathrm{T}[7]=4 \mathrm{~A} 7 \mathrm{~B} 2631]$ AND 00FFFFFF XOR 2984AE28 $=29 \mathrm{FF} 8819$

$\mathrm{n}=8$

$\mathrm{X}=(2984 \mathrm{AE} 28$ AND FF7FFFFF $)+$ FF7256A9 $=$ 287704D 1

$\mathrm{T}[8]=\mathrm{BE7C74C} 3]$ AND 00FFFFFF XOR 287704D1 = 280B7012

$\mathrm{n}=9$

$\mathrm{X}=(287704 \mathrm{D} 1 \mathrm{AND}$ FF7FFFFF $)+$ FF7256A9 $=$ 27E95B7A 
$\mathrm{T}[9]=\mathrm{E} 1 \mathrm{~EB} 00 \mathrm{~B} 6]$ AND 00FFFFFF XOR 27E95B7A = 27025BCC

$\mathrm{n}=10$

$\mathrm{X}=(27 \mathrm{E} 95 \mathrm{~B} 7 \mathrm{~A}$ AND FF7FFFFF $)+$ FF7256A9 $=$ 26DBB223

$\mathrm{T}[10]=5 \mathrm{D} 35 \mathrm{C} 7 \mathrm{~F} 1]$ AND 00FFFFFF XOR 26DBB223 = 26EE75D2

$\mathrm{n}=11$

$\mathrm{X}=(26 \mathrm{DBB} 223 \mathrm{AND}$ FF7FFFFF $)+\mathrm{FF} 7256 \mathrm{~A} 9=25 \mathrm{CE} 08 \mathrm{CC}$

$\mathrm{T}[11]=\mathrm{D} 901 \mathrm{E} 23 \mathrm{C}]$ AND 00FFFFFF XOR 25CE08CC = 25CFEAF0

$\mathrm{n}=12$

dan seterusnya....

LANGKAH 8 - Untuk n = 0 sampai 255, lakukan prosedur berikut.

$\mathrm{n}=0$

Temp $=\mathrm{T}[224]$ XOR X AND $255=50 \mathrm{CCC} 0 \mathrm{AD}$ XOR 000000E0 AND $255=0000004 \mathrm{D}$

$\mathrm{T}[0]=\mathrm{T}[77]=\mathrm{E} 3 \mathrm{D} 54644$

$\mathrm{T}[224]=\mathrm{T}[1]=2 \mathrm{~F} 8 \mathrm{~B} 7610$

$\mathrm{n}=1$

Temp $=$ T[225] XOR X AND 255 $=$ 4FBF34E3 XOR 000000E0 AND $255=00000003$

$\mathrm{T}[1]=\mathrm{T}[3]=2 \mathrm{D} 05 \mathrm{CCF} 9$

$\mathrm{T}[224]=\mathrm{T}[2]=2 \mathrm{E} 228050$

Sampai $10 \ldots$

$\mathrm{n}=10$

Temp $=\mathrm{T}[234]$ XOR X AND $255=46 \mathrm{BADA} 9 \mathrm{~F}$ XOR 000000E0 AND $255=0000007 \mathrm{~F}$

$\mathrm{T}[10]=\mathrm{T}[127]=\mathrm{B} 189 \mathrm{~B} 3 \mathrm{FD}$

$\mathrm{T}[224]=\mathrm{T}[11]=25 \mathrm{CFEAF0}$

Dan seterusnya,.....

Nilais-bokuntukkunci‘STMIK BUDIDARMA’adalah :

$\mathrm{T}[0]=\mathrm{E} 3 \mathrm{D} 54644$

$\mathrm{T}[1]=2 \mathrm{D} 05 \mathrm{CCF} 9$

$\mathrm{T}[2]=27025 \mathrm{BCC}$

$\mathrm{T}[3]=68 \mathrm{EEF} 7 \mathrm{AE}$

$\mathrm{T}[4]=\mathrm{BC} 2992 \mathrm{DF}$

$\mathrm{T}[5]=\mathrm{EE} 50 \mathrm{CD} 18$

$\mathrm{T}[6]=673 \mathrm{~B} 98 \mathrm{DF}$

$\mathrm{T}[7]=3 \mathrm{BABA} 719$

$\mathrm{T}[8]=531835 \mathrm{E} 2$

$\mathrm{T}[9]=9 \mathrm{~B} 99 \mathrm{C} 275$

$\mathrm{T}[10]=\mathrm{B} 189 \mathrm{~B} 3 \mathrm{FD}$

$\mathrm{T}[11]=\mathrm{C} 9 \mathrm{BF} 4 \mathrm{~B} 0 \mathrm{E}$

$\mathrm{T}[12]=609 \mathrm{FF} 4 \mathrm{BF}$

$\mathrm{T}[13]=\mathrm{F} 186130 \mathrm{C}$

$\mathrm{T}[14]=1830 \mathrm{EA} 55$

$\mathrm{T}[15]=8 \mathrm{C} 21 \mathrm{AF} 54$

$\mathrm{T}[16]=46 \mathrm{BADA} 9 \mathrm{~F}$ 
$\mathrm{T}[17]=\mathrm{DD} 484478$

$\mathrm{T}[18]=3229626 \mathrm{C}$

$\mathrm{T}[19]=4 \mathrm{~B} 96 \mathrm{EAA} 2$

$\mathrm{T}[20]=\mathrm{BE} 6 \mathrm{~A} 767 \mathrm{C}$

$\mathrm{T}[21]=37 \mathrm{C} 1 \mathrm{D} 252$

$\mathrm{T}[22]=\mathrm{E} 6869 \mathrm{~B} 95$

$\mathrm{T}[23]=\mathrm{CCA} 727 \mathrm{E} 0$

$\mathrm{T}[24]=\mathrm{E} 6869 \mathrm{~B} 95$

$\mathrm{T}[25]=7 \mathrm{~EB} 0 \mathrm{~F} 5 \mathrm{DE}$

$\mathrm{T}[26]=\mathrm{BC} 2992 \mathrm{DF}$

$\mathrm{T}[27]=34 \mathrm{D} 0 \mathrm{~A} 54 \mathrm{C}$

$\mathrm{T}[28]=84 \mathrm{~F} 4 \mathrm{EAE} 8$

$\mathrm{T}[29]=72 \mathrm{FD} 1692$

$\mathrm{T}[30]=\mathrm{A} 4 \mathrm{~B} 5 \mathrm{~A} 8 \mathrm{~F} 8$

Sampai menuju ;

$\mathrm{T}[256]=30 \mathrm{DC} 4957$

\subsection{Proses Pembentukan Kunci}

Proses pembentukan kunci memerlukan inputkunci dengan panjang 128 bit biner atau 16 karakter ascii. Pertama-tama, input kunci dipecah menjadi 4 kelompok dan di-set sebagai nilai awal dari variabel $\mathrm{A}_{0}, \mathrm{~B}_{0}, \mathrm{C}_{0}, \mathrm{D}_{0}$. Kemudian isi variabel $\mathrm{A}, \mathrm{B}, \mathrm{C}$ dan $\mathrm{D}$ dan ulangi sebanyak n-putaran yang di-input.

$$
\begin{aligned}
& A_{i+1}=M\left(A_{i}, D_{i}\right) \\
& B_{i+1}=M\left(B_{i}, A_{i+1}\right) \\
& C_{i+1}=M\left(C_{i}, B_{i+1}\right) \\
& D_{i+1}=M\left(D_{i}, C_{i+1}\right)
\end{aligned}
$$

Fungsi $\mathrm{M}(\mathrm{X}, \mathrm{Y})=(\mathrm{X}+\mathrm{Y})>>8$ XOR $\mathrm{T}\left[(\mathrm{X}+\mathrm{Y})\right.$ AND 255]. Nilai dari $\mathrm{D}_{\mathrm{i}}$ merupakan nilai dari kunci $\mathrm{K}_{\mathrm{i}}$. Proses ini dapat dilihat pada contoh berikut :

Misalkan inputkey : 'STMIK BUDIDARMA' dan putaran kunci sebanyak 4 kali, maka proses pembentukan kunci dalam heksadesimal adalah sebagai berikut :

Kunci 'STMIK BUDIDARMA' diubah dalam bentuk BINER= 100110101010110100000110 00110111

Kunci 'STMIK BUDIDARMA' diubah dalam bentuk biner $=010100110101010001001101$ 010010010100101100100000010000100101010101000100010010010100010001000001 01010010010011010100000100100000

Pecah kunci menjadi 4 kelompok dan masukkan ke $\mathrm{A}(0), \mathrm{B}(0), \mathrm{C}(0)$ dan $\mathrm{D}(0)$.

$\mathrm{A}(0)=01010011010101000100110101001001$

$\mathrm{B}(0)=01001011001000000100001001010101$

$\mathrm{C}(0)=01000100010010010100010001000001$

$\mathrm{D}(0)=01010010010011010100000100100000$

\section{KUNCI PUTARAN 1}

FungsiM $(\mathrm{A}[0], \mathrm{D}[0])=$ FungsiM(01010011010101000100110101001001,01010010010011010100000100100000) $(01010011010101000100110101001001+01010010010011010100000100100000)>>8$ XOR $\mathrm{T}[(01010011010101000100110101001001+01010010010011010100000100100000)$ AND 


$\begin{array}{llllll}255(10)] & = & 10100101101000011000111001101001>>8 & \text { XOR } & \text { T }[105] & = \\ 00000000101001011010000110001110 & \text { XOR } & 10001010011111110111101101111110 & = \\ 10001010110110101101101011110000 & & & \end{array}$

$\mathrm{A}[1]=10001010110110101101101011110000$

FungsiM(B[0],A[1])

FungsiM(01001011001000000100001001010101,10001010110110101101101011110000) $(01001011001000000100001001010101+10001010110110101101101011110000)>>8$ $\mathrm{T}[(01001011001000000100001001010101+10001010110110101101101011110000)$ $255(10)]=11010101111110110001110101000101>>8 \quad X O R \quad T[69]$ $00000000110101011111101100011101 \quad$ XOR 01101110001100010011011000011100 01101110111001001100110100000001

$\mathrm{B}[1]=01101110111001001100110100000001$

FungsiM(C[0],B[1])

FungsiM(01000100010010010100010001000001,01101110111001001100110100000001) $(01000100010010010100010001000001+01101110111001001100110100000001)>>8$ $\mathrm{T}[(01000100010010010100010001000001+01101110111001001100110100000001)$ $255(10)]=10110011001011100001000101000010>>8 \quad X O R \quad T[66]$ $00000000101100110010111000010001 \quad$ XOR 01010101111110100111100000101110 01010101010010010101011000111111

$\mathrm{C}[1]=01010101010010010101011000111111$

FungsiM(D[0],C[1])

FungsiM(01010010010011010100000100100000,01010101010010010101011000111111) $(01010010010011010100000100100000+01010101010010010101011000111111)>>8$ $\mathrm{T}[(01010010010011010100000100100000+01010101010010010101011000111111)$ $255(10)]=10100111100101101001011101011111>>8 \quad X O R \quad \mathrm{~T}[95]$ $00000000101001111001011010010111 \quad$ XOR $\quad 01100111001110111001100011011111$ 01100111100111000000111001001000

$\mathrm{D}[1]=01100111100111000000111001001000$

\section{KUNCI PUTARAN 2}

Sampai:

FungsiM(D[3],C[4])

FungsiM(01101101001100001110001101111110,10011011100111011001011010111011) $(01101101001100001110001101111110+10011011100111011001011010111011)>>8$ $\mathrm{T}[(01101101001100001110001101111110+10011011100111011001011010111011) \quad$ AND $255(10)]=00001000110011100111101000111001>>8 \quad X O R \quad T[57]=$ $00000000000010001100111001111010 \quad$ XOR $\quad 10011010101001011100100001001101=$ 10011010101011010000011000110111

$\mathrm{D}[4]=10011010101011010000011000110111$

KUNCI $=$ D[4] = 10011010101011010000011000110111

\subsection{Proses Enkripsi}

Proses enkripsi dari metode twofish untuk menghasilkan ciphertext adalah berupa hasil operasi XOR dari plaintext dan 128 bit kunci yang dihasilkan dari proses pembentukan kunci. 
Contoh :

PlainTeks $=$ SAYA SEDANG MAKAN NASI

Key $=$ STMIK BUDIDARMA

Maka adapun hasil proses enkripsinya adalah sebagai berikut:

Plain Text : 'SAYA SEDANG MAKAN NASI

Kode ascii dari 'S' = 01010011

Kode ascii dari 'A' $=01000001$

Kode ascii dari ' $\mathrm{Y}$ ' $=01011001$

Kode ascii dari 'A' $=01000001$

Kode ascii dari ' ' $=00100000$

Kode ascii dari ' ' $=00100000$

Kode ascii dari ' $\mathrm{N}$ ' $=01001110$

Kode ascii dari 'A' = 01000001

Kode ascii dari 'S' $=01010011$

Kode ascii dari 'I' = 00100001

Plain Text (dalam biner) $=010000010101100101010101001000000101001101000101$ $\begin{array}{lllllllll}01000100 & 01000001 & 01001110 & 0100011100100000 & 01001101 & 01000001 & 0100101101000001\end{array}$ 010011100010000001000001010110010100000101001101001000000

Kunci dari proses pembentukan kunci $=10011010101011010000011000110111$

Cipher Text $=$ Plain Text XOR Key

01010011 XOR $10011010=11001001=$ 'É'

01000001 XOR $00110111=01110110=$ 'v'

01011001 XOR $00000110=01011111=$,'

01000001 XOR $00110111=01110110=\overline{~ ' v}^{\prime}$

00100000 XOR $00110111=00010111={ }^{\prime}, '$

01010011 XOR $10011010=11001001=$ 'É' $^{\prime}$

01000101 XOR $10101101=11101000=$ 'è'

01000100 XOR $00000110=01000010=$ 'B'

01000001 XOR $00110111=01110110=$ 'v'

01001110 XOR $10011010=11010100=$ 'Ô' $^{\prime}$

01000111 XOR $10101101=11101010=$ 'ê' $^{\prime}$

00100000 XOR $00000110=00100110=$ ' $\&$ '

01001101 XOR $00110111=01111010=$ 'z'

01000001 XOR $10011010=11011011=$ 'Û'

01001011 XOR $10101101=11100110=$ ' $\mathfrak{}$

01000001 XOR $00000110=01000111={ }^{\prime} \mathrm{G}^{\prime}$

01001110 XOR $00110111=01111001=$ 'y'

00100000 XOR $10011010=10111010={ }^{\prime \prime \prime}$

01001110 XOR $10011010=11010100=$ 'Ô' $^{\prime}$

01000001 XOR $00110111=01110110=$ 'v'

01011001 XOR $00000110=01011111=$,'

01001011 XOR $10101101=11100110=\bar{x}^{\prime}$ '

Hasil proses enkripsi = Évìv_ÉèBvÔê\&zÛæGyo_ÔvÉz

\subsection{Proses Dekripsi}


Proses dekripsi dari metode twofish untuk menghasilkan plaintext adalah berupa hasil operasi XOR dari ciphertext dan 128 bit kunci yang dihasilkan dari proses pembentukan kunci.

Plaintext $(\mathrm{P})=$ Ciphertext $(\mathrm{C}) \mathrm{XOR} \operatorname{Key}(\mathrm{K})$

Cipher Text : 'Évìv_ÉèBvÔê\&zÛæayo_ÔvÉz

Kode ascii dari 'É' = 11001001

Kode ascii dari ' $v$ ' $=01110110$

Kode ascii dari 'î' $=11101100$

Kode ascii dari ' $\mathrm{v}$ ' $=01110110$

Kode ascii dari '_' $=00010111$

Kode ascii dari 'É' $=11001001$

Kode ascii dari 'è' $=11101000$

Kode ascii dari 'B' $=01000010$

Kode ascii dari ' $v$ ' $=01110110$

Kode ascii dari 'Ô' = 11010100

Kode ascii dari 'ê' $=11101010$

Kode ascii dari ' $\&$ ' $=00100110$

Kode ascii dari ' $\mathrm{z}$ ' $=01111010$

Kode ascii dari ' $\hat{\mathrm{U}}$ ' $=11011011$

Kode ascii dari 'æ' $=11100110$

Kode ascii dari 'G' $=01000111$

Kode ascii dari 'y' $=01111001$

Kode ascii dari ${ }^{\prime 0 \prime}=10111010$

Kode ascii dari 'Ô' = 11010100

Kode ascii dari 'y ' = 11001001

Kode ascii dari 'É' = 11001011

Kode ascii dari ' $v$ ' $=11001010$

Cipher Text (dalam biner $)=$

11011011111101000101001100010111110010011110100001000010011101101101010011101010 00100110011110101101101111100110010001110111100110111010111011000101111101110110 110101111000110101

Kunci dari proses pembentukan kunci $=10011010101011010000011000110111$

Plain Text $=$ Cipher Text XOR Key

11001001 XOR $10011010=01010011=$ 'S'

11011011 XOR $10011010=01000001=$ 'A'

11110100 XOR $10101101=01011001={ }^{\prime} Y^{\prime}$

01110110 XOR $00110111=01000001={ }^{\prime} \mathrm{A}^{\prime}$

00010111 XOR $00110111=00100000={ }^{\prime} '$

11001001 XOR $10011010=01010011=$ 'S'

11101000 XOR $10101101=01000101={ }^{\prime} E^{\prime}$

01000010 XOR $00000110=01000100=$ 'D'

01110110 XOR $00110111=01000001={ }^{\prime} \mathrm{A}$ '

11010100 XOR $10011010=01001110={ }^{\prime} \mathrm{N}^{\prime}$

11101010 XOR $10101101=01000111={ }^{\prime} \mathrm{G}^{\prime}$

00100110 XOR $00000110=00100000={ }^{\prime}{ }^{\prime}$

01111010 XOR $00110111=01001101={ }^{\prime} \mathrm{M} '$

11011011 XOR $10011010=01000001={ }^{\prime} \mathrm{A}$ 


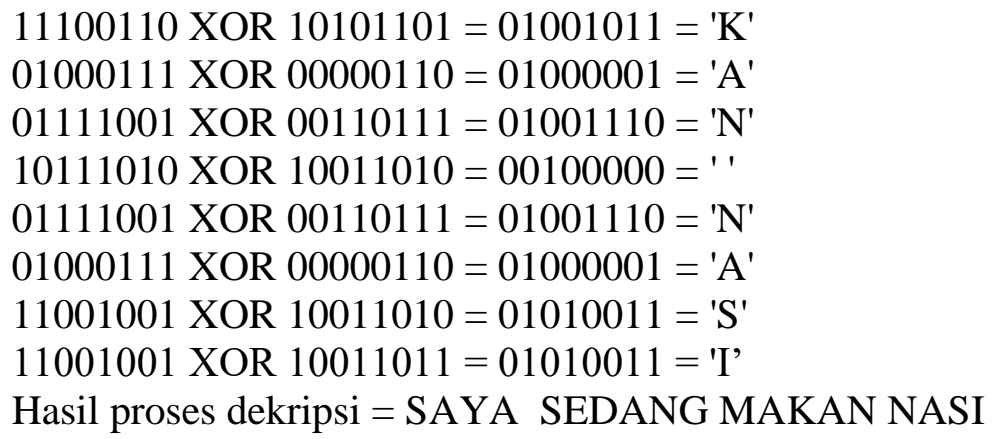

\section{KESIMPULAN}

Setelah melakukan perancangan dan implementasi maka penulis dapat memberikan beberapa kesimpulan sebagai berikut :

1. Proses penyandian data pada record menggunakan metode twofish agar data tersebut tidak diketahui oleh pihak yang tidak bertanggung jawab.

2. Proses penyandian record dengan menggunakan metode twofish dilakukan dengan cara pembentukan S-Box proses pembentukan kunci proses enkripsi dan proses deskripsi sehinga data atau recordakan tersandi.

3. Dalam penerapan aplikasi penyandian record menggunakan sofware Microsoft visual basic net 2008.

\section{DAFTAR PUSTAKA}

[1] R. Sadikin, Kriptografi untuk keamanan jaringan. Penerbit ANDI, 2012.

[2] D. Ariyus, "Kriptografi keamanan data dan komunikasi," Yogyakarta Graha Ilmu, 2006.

[3] R. Santi, "Implementasi Algoritma Enkripsi Playfair pada File Teks," None, vol. 15, no. 1, p. 246766, 2010.

[4] R. Munir, "Kriptografi," Inform. Bandung, 2006.

[5] A. Farisi, "Analisis Kinerja Algoritma Kriptografi Kandidat Advanced Encryption Standard (AES) pada Smartphone," JATISI (Jurnal Tek. Inform. dan Sist. Informasi), vol. 4, no. 2, pp. 199-208, 2018, doi: 10.35957/jatisi.v4i2.103.

[6] D. R. Yunia, Adiwijawa, and Setyorini, "Analisis dan implementasi algoritma twofish pada penyandian citra digital," pp. 0-5, 2012.

[7] M. Qamal, "Kriptografi File Citra Menggunakan Algoritma Tea (Tiny Encryption Algorithm)," TECHSI - J. Penelit. Tek. Inform., 2014.

[8] Z. Hercigonja, "Comparative Analysis of Cryptographic Algorithms," Int. J. Digit. Technol. Econ., vol. 1, no. 2, pp. 127-134, 2016.

[9] A. M. Hasibuan, "Rancang Bangun Aplikasi Keamanan Data Menggunakan Metode AES Pada Smartphone," MEANS (Media Inf. Anal. dan Sist., vol. 2, no. 1, pp. 29-35, Jun. 2017, doi: 10.17605/JMEANS.V2I1.20.

[10] D. A. Trianggana and H. Latipa Sari, "Analisis Perbandingan Kinerja Algoritma Blowfish Dan Algoritma Twofish Pada Proses Enkripsi Dan Dekripsi," Pseudocode, vol. 2, no. 1, pp. 37-44, 2015, doi: 10.33369/pseudocode.2.1.37-44. 